\title{
Assessment of Human Exposure to Deoxynivalenol, Ochratoxin A, Zearalenone and Their Metabolites Biomarker in Urine Samples Using LC-ESI-qTOF
}

\author{
Dionisia Carballo ${ }^{1,+}$, Noelia Pallarés ${ }^{2,+}\left(\mathbb{D}\right.$, Emilia Ferrer ${ }^{2} * \mathbb{D}$, Francisco J. Barba ${ }^{2, *(D)}$ and Houda Berrada 2 (D) \\ 1 Faculty of Agricultural Science, National University of Asunción, San Lorenzo 2160, Paraguay; \\ dionisia.carballo@agr.una.py \\ 2 Department of Preventive Medicine and Public Health, Food Science, Toxicology and Forensic Medicine, \\ Faculty of Pharmacy, University of Valencia, 46100 Burjassot, Valencia, Spain; Noelia.pallares@uv.es (N.P.); \\ houda.berrada@uv.es (H.B.) \\ * Correspondence: emilia.ferrer@uv.es (E.F.); francisco.barba@uv.es (F.J.B.); \\ Tel.: +34-963-544-950 (E.F.); +34-963-544-972 (F.J.B.) \\ + Both authors contributed equally to this manuscript.
}

Citation: Carballo, D.; Pallarés, N.; Ferrer, E.; Barba, F.J.; Berrada, H. Assessment of Human Exposure to Deoxynivalenol, Ochratoxin A, Zearalenone and Their Metabolites Biomarker in Urine Samples Using LC-ESI-qTOF. Toxins 2021, 13, 530. https://doi.org/10.3390/ toxins13080530

Received: 20 June 2021

Accepted: 26 July 2021

Published: 28 July 2021

Publisher's Note: MDPI stays neutral with regard to jurisdictional claims in published maps and institutional affiliations.

Copyright: () 2021 by the authors. Licensee MDPI, Basel, Switzerland. This article is an open access article distributed under the terms and conditions of the Creative Commons Attribution (CC BY) license (https:// creativecommons.org/licenses/by/ $4.0 /)$.

\begin{abstract}
Human are exposed to a wide range of mycotoxins through dietary food intake, including processed food. Even most of the mycotoxin exposure assessment studies are based on analysis of foodstuffs, and evaluation of dietary intake through food consumption patterns and human biomonitoring methods are rising as a reliable alternative to approach the individual exposures, overcoming the limitations of the indirect dietary assessment. In this study, human urine samples were analyzed, seeking the presence of deoxynivalenol (DON), ochratoxin A (OTA), zearalenone (ZEA), and their metabolites. For this purpose, 40 urine samples from female and male adult residents in the city of Valencia (Spain) were evaluated by liquid chromatography quadrupole time-of-flight mass spectrometry (LC-ESI-qTOF) after salting-out liquid-liquid extraction. Analytical data showed that $72.5 \%$ of analyzed samples were contaminated by at least one mycotoxin at variable levels. The most prevalent mycotoxins were de-epoxy DON (DOM-1) (53\%), ZEA (40\%), and $\alpha$-zearalenol ( $\alpha$ ZOL) (43\%), while OTA was only detected in one sample. The mean concentrations in positive samples were DON (9.07 ng/mL), DOM-1 (20.28 ng/mL), ZEA (6.70 ng/mL), ZEA-14 glucoside (ZEA-14-Glc) (12.43 ng/mL), $\alpha Z O L ~(27.44 \mathrm{ng} / \mathrm{mL}), \alpha Z O L-14$ glucoside $(\alpha Z O L-14-G l c)(12.84 \mathrm{ng} / \mathrm{mL})$, and OTA (11.73 ng/mL). Finally, probable daily intakes (PDIs) were calculated and compared with the established tolerable daily intakes (TDIs) to estimate the potential risk of exposure to the studied mycotoxins. The calculated PDI was below the TDI value established for DON in both female and male adults, reaching a percentage up to $30 \%$; however, this percentage increased up to $92 \%$ considering total DON (DON + DOM-1). On the other hand, the PDI obtained for ZEA and its metabolites were higher than the TDI value fixed, but the low urine excretion rate $(10 \%)$ considered should be highlighted. Finally, the PDI calculated in the detected positive sample for OTA exceeded the TDI value. The findings of the present study confirm the presence of the studied mycotoxins and their metabolites as some of the most prevalent in urine.
\end{abstract}

Keywords: mycotoxins; biomarkers; metabolites; LC-ESI-qTOF; urine; risk assessment

Key Contribution: The findings of the present study confirm the presence of deoxynivalenol (DON), ochratoxin A (OTA), zearalenone (ZEA), and their metabolites as some of the most prevalent in urine. The development of biomarker approaches will greatly help in evaluating human exposure to mycotoxins, among other food contaminants.

\section{Introduction}

Mycotoxins are toxic secondary metabolites produced by various fungi on diverse agricultural commodities. The accumulation of mycotoxins in food and feedstuffs represent 
a major threat to human and animal health, as they are related to different toxic effects, such as cancer induction, mutagenicity, nephrotoxicity, estrogenicity, and urogenital and nervous disorders. Contaminated food consumption is the major source of human exposure to mycotoxins [1,2]. Thus, the food industry is looking for technologies that can remove mycotoxins from food materials [3].

Traditional exposure assessment to mycotoxins involves foodstuff analysis and the estimation of average consumption patterns. However, this approach presents some disadvantages, such as the lack of information at individual exposure, and the bioavailability and toxicokinetics [4]. An alternative way to evaluate the exposure can be through biomarkers. A biomarker exposure is defined as a biological measure that is correlated with the quantity of toxic compound ingested [5]. Biomarkers allow more accurate assessment of the exposure at an individual level because their measurements include the individual variation in absorption, distribution, metabolism, and excretion [6,7].

Typical biomarkers include parent toxins themselves, protein or DNA adducts, and/or the major phase I or II metabolites (glucuronide conjugates) that may be measured in biological fluids, such as plasma/serum or urine, and are related to the intake of mycotoxins through contaminated food [4]. In this context, the analysis of mycotoxins and their metabolites in human urine may provide a very suitable alternative for the evaluation of exposure to mycotoxins. In addition, urine collection constitutes an easy and noninvasive sampling method.

Biomarkers of mainly reported mycotoxins have been previously studied in urine [8-11]. In fact, deoxynivalenol (DON), zearalenone (ZEA), ohratoxin A (OTA), and their selected metabolites are some of the most frequently reported mycotoxins in urine. ZEA commonly occurs in various cereal crops and processed grains (i.e., wheat, rice, and corn). It produces estrogenic effects, which can have adverse effects on the genital organs and reproductive system. After oral administration, ZEA is rapidly absorbed and subsequently degraded into $\alpha$-zearalenol $(\alpha$-ZOL) and $\beta$-zearalenol $(\beta$-ZOL), which may be additionally reduced into $\alpha$-zearalanol ( $\alpha$-ZAL) and $\beta$-zearalanol ( $\beta$-ZAL). $\alpha$-ZAL is metabolized into its isomer, $\beta$-ZAL, and, to a lesser extent, into zearalanone (ZAN) [12]. These compounds are partially conjugated with sulfonic or glucuronic acid to produce, i.e., ZEA-14-glucuronic acid (ZEA-14-GlcA), ZAN-14-GlcA, $\alpha$-ZOL-14- GlcA, $\beta$-ZOL-14- GlcA, that are excreted in the urine [13]. The human urinary excretion of ZEA corresponds to approximately $10 \%$ of the administrated dose, ZEA glucuronides and $\alpha$-ZOL being the main metabolites excreted [14].

DON is a natural contaminant of cereal grains (i.e., maize, wheat, barley, and oats) and cereal-based processed food (i.e., cereals, bread, and mat beer). DON is related to adverse effects, including vomiting, nausea, anorexia, delayed growth, neurological changes, and impairments in reproductive and immune function. DON has a short life of excretion; it is detectable in high amounts in the serum immediately after ingestion, but it is rapidly cleared from the bloodstream. The main fraction of DON can be excreted in urine in its unmetabolized form, but also as glucuronide conjugates (DON-GlcA) including the deoxynivalenol-3-glucuronide (DON-3-GlcA) and deoxynivalenol-15-glucuronide (DON15-GlcA). Furthermore, the de-epoxy DON (DOM-1), a detoxification product of DON formed by gut microbiota, can also be detected in urine [15]. In humans, the estimated percentage of excretion corresponds to $72.3 \%$ of the administered dose [16].

OTA is a natural contaminant of many foodstuffs, such as cereal products, coffee, cacao, beer, grape juice, raisins, wine, and spices. Regarding its toxicity, OTA has been associated with nephrotoxic and carcinogenic adverse effects. OTA is biotransformed by cytochrome P450 enzymes to their hydroxyochratoxin A metabolites, which are less toxic. In humans, ochratoxin alpha (OT $\alpha)$ is the major metabolite of OTA and is formed in the gastrointestinal tract by hydrolysis. OT $\alpha$ is further metabolized to a glucuronide and possibly to a sulfate conjugate, being more efficiently cleared from the circulation system and easily excreted in the urine [17]. The percentage of OTA excreted in urine is nearly $50 \%$ of the OTA ingested [18]. 
Enzymatic hydrolysis with $\beta$-glucuronidase is required to release the parent mycotoxin from the mycotoxins-glucuronides. After enzymatic deconjugation, the total amount of (free+conjugated) mycotoxins and their metabolites can be used to assess mycotoxin exposure.

This study was conducted with the aim of assessing human exposure to mycotoxins through multi-biomarker analysis in 40 urine samples of different volunteers. For this purpose, urine samples were extracted by salting-out liquid-liquid extraction (SALLE) and determined using liquid chromatography coupled with quadrupole time-of-flight mass spectrometry with electrospray ionization (LC-ESI-QTOF-MS) system. Finally, to estimate the potential risk of exposure to the studied mycotoxins, the probable daily intakes (PDIs) were calculated and compared with the tolerable daily intakes (TDIs) established.

\section{Results and Discussion}

\subsection{Mycotoxin Contents in Urine}

DON, DOM-1, ZEA, zearalenone-14-glucoside (ZEA-14-Glc), $\alpha$ ZOL, $\alpha$-zearalenol-14glucoside ( $\alpha$ ZOL-14-Glc), and OTA were the main mycotoxins and metabolites identified in the urinary samples. The incidence, minimum and maximum concentrations, and mean of positives are shown in Table 1. Among all, ZEA and its metabolites ZEA-14Glc, $\alpha Z O L, \alpha Z O L-14-G l c$, and DOM-1 were the biomarkers with the highest incidence in urinary samples, showing percentages of $40 \%, 18 \%, 43 \%, 20 \%$, and $53 \%$, respectively. These biomarkers were detected in urinary samples with concentrations between $<$ LOQ and $49.45 \mathrm{ng} / \mathrm{mL}$. Figure 1 shows the chromatogram of a human urine sample containing ZEA-14-Glc.

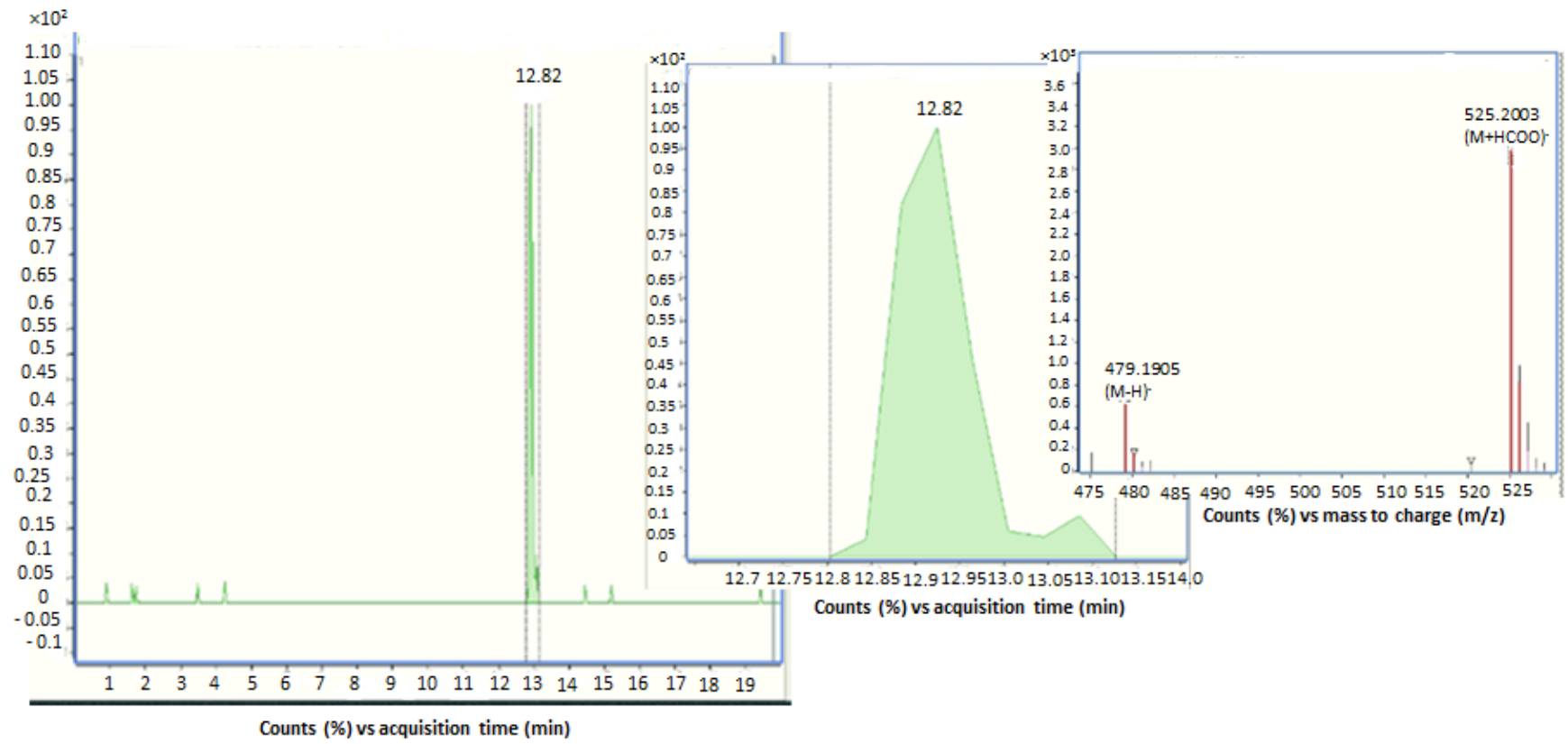

Figure 1. LC-ESI-qTOF-MS chromatogram of a human urine sample naturally contaminated by zearalenone-14-glucoside (ZEA-14-Glc).

Regarding ZEA and its metabolites, the mean concentration of positives determined in the present work were $6.7 \mathrm{ng} / \mathrm{mL}$ for ZEA, $12.43 \mathrm{ng} / \mathrm{mL}$ for ZEA-14-Glc, $27.44 \mathrm{ng} / \mathrm{mL}$ for $\alpha \mathrm{ZOL}$, and $12.84 \mathrm{ng} / \mathrm{mL}$ for $\alpha \mathrm{ZOL}-14-G l c$ (Table 1 ). These values were higher than those observed by Li et al. [12], even though they did not include hydrolyzed samples. These authors reported very low incidences for ZEA and $\alpha$ ZOL $(1.3 \%)$, with amounts ranging from $<\mathrm{LOQ}$ to $0.05 \mathrm{ng} / \mathrm{mL}$. Moreover, they detected ZAN $(0.3 \%)$ and $\beta Z O L(1 \%)$, but these two ZEA metabolites were not identified in the present study. In another study, performed by Solfrizzo et al. [19] in hydrolyzed samples, higher incidences (about 100\%) 
were found for $\beta Z O L, \alpha Z O L$, and ZEA, but at lower mean concentrations, with values of 0.090, 0.077, and $0.057 \mathrm{ng} / \mathrm{mL}$, respectively. Ediage et al. [8] also reported lower incidences (around 10\%) but more similar values than those obtained in the present study, despite the fact that ZEA-14-Glc, $\alpha$ ZOL, and $\alpha$ ZOL-14-Glc were not detected by these authors. ZEA and $\beta Z O L$ were reported at contents ranging from $<\mathrm{LOQ}$ to $12.6 \mathrm{ng} / \mathrm{mL}$ and from 4 to $24.8 \mathrm{ng} / \mathrm{mL}$, respectively, by these authors. Sarkanj et al. [20] observed similar contents to the present study and a higher incidence for ZEA in hydrolyzed urine samples, with contents ranging from 0.03 to $19.99 \mathrm{ng} / \mathrm{mL}$ and an incidence of $81.7 \%$; however, lower incidences and contents were reported for $\alpha \mathrm{ZOL}$, at $4.2 \%$ and up to $2.52 \mathrm{ng} / \mathrm{mL}$.

OTA was only detected in one sample, at a concentration of $11.73 \mathrm{ng} / \mathrm{mL}$ (Table 1). Comparing these results with the information available in the literature, the contents reported in the available literature are, in general, lower. Ali et al. [17] reported all positive samples for OTA in the range of $0.02-1.82 \mathrm{ng} / \mathrm{mL}$. However, higher amounts were observed for OT $\alpha(0.01-14.25 \mathrm{ng} / \mathrm{mL})$. Other studies have also reported notable incidence for OTA, even at lower levels, below $0.14 \mathrm{ng} / \mathrm{mL}[10,19]$.

DOM-1, the metabolite produced from DON by intestinal microbiota, was detected in 21 of 40 analyzed samples (53\%), with a positive mean of $20.28 \mathrm{ng} / \mathrm{mL}$ (Table 1$)$. In another study, performed in Spain, Vidal et al. [10] registered DOM-1 with high incidences, at 96\% of urine samples of volunteers following a normal diet, and at $78 \%$ of urine samples of volunteers with a temporary diet restriction, including food commonly associated with mycotoxins presence. The mean concentrations determined were 23 and $12.9 \mathrm{ng} / \mathrm{mL}$, respectively. In France, Turner et al. [21] also obtained a lower percentage (34\%) of positive urine samples, with a mean concentration of $0.2 \mathrm{ng} / \mathrm{mL}$. In the UK, Turner et al. [22] only observed $2 \%$ of urinary samples as positive, at a mean concentration of $0.65 \mathrm{ng} / \mathrm{mL}$. Contrary to the present study, Cunha et al. [23] did not find DOM-1 in any of the analyzed urinary sample.

The parent mycotoxin, DON, was detected in the present work in 9 of 40 analyzed samples $(23 \%)$, with a mean of positives of $9.07 \mathrm{ng} / \mathrm{mL}$ (Table 1$)$. Similar results were previously reported by Rodriguez-Carrasco et al. [24], who quantified a mean of positive samples for free DON of $7.9 \mathrm{ng} / \mathrm{mL}$ in $50 \%$ of analyzed urinary samples. Moreover, Solfrizzo et al. [19] observed that $96 \%$ of samples were positive for DON after the hydrolysis process, with a mean concentration of $11.89 \mathrm{ng} / \mathrm{mL}$. Contrary to these results, Warth et al. [25] did not determine free DON in analyzed urinary samples. Niknejad et al. [26] studied the multi-mycotoxin urinary levels in healthy volunteers and esophageal cancer patients, and reported DON presence in only one sample from healthy volunteers at a concentration of $8.42 \mu \mathrm{g} / \mathrm{L}$.

Table 1. Incidence (\%), minimum and maximum levels $(\mathrm{ng} / \mathrm{mL})$, and mean of positives (ng/mL) of mycotoxins and its metabolites detected in urinary samples.

\begin{tabular}{cccc}
\hline Mycotoxin & $\begin{array}{c}\text { Number and Percentage of } \\
\text { Positive Samples }\end{array}$ & $\begin{array}{c}\text { Range Concentration } \\
\text { (ng/mL) }\end{array}$ & Mean of Positives (ng/mL) \\
\hline DON & $9 / 40(23 \%)$ & $<$ LOQ-18.67 & $9.07 \pm 7$ \\
DOM-1 & $21 / 40(53 \%)$ & $<$ LOQ-49.45 & $20.28 \pm 4$ \\
ZEA & $16 / 40(40 \%)$ & $<$ LOQ-29.01 & $6.70 \pm 7$ \\
ZEA-14-Glc & $7 / 40(18 \%)$ & $2.87-28.80$ & $12.43 \pm 9$ \\
$\alpha Z O L$ & $17 / 40(43 \%)$ & $<$ LOQ-43.68 & $27.44 \pm 20$ \\
$\alpha$ ZOL-14-Glc & $8 / 40(20 \%)$ & $<$ LOQ-29.20 & $12.84 \pm 14$ \\
OTA & $1 / 40(3 \%)$ & 11.73 & 11.73 \\
\hline
\end{tabular}

\subsection{Exposure Assessment}

The calculated PDI values for ZEA and total ZEA (ZEA and its metabolites: ZEA-14Glc, $\alpha Z O L, \alpha Z O L-14-G l c)$ in positive samples were, for both males and females, higher than the TDI established $(0.25 \mu \mathrm{g} / \mathrm{kg}$ bw/day). This was also observed when the PDI was calculated under LB and UB scenarios (Table 2). However, the low ZEA excretion 
percentage in urine $(10 \%)$ considered to calculate the PDI should be highlighted. Contrary to these results, in Italy, Solfrizzo et al. [19] estimated a mean PDI value in urine samples about ten times below the TDI established; however, these authors considered a higher mean urinary excretion rate for ZEA (36.8\%).

Table 2. Mycotoxins risk assessment based on the mycotoxin biomarker urinary levels among the participants.

\begin{tabular}{|c|c|c|c|c|c|c|c|c|c|c|c|c|c|}
\hline \multirow{3}{*}{ Mycotoxin } & \multirow{3}{*}{$\begin{array}{c}\text { Tolerable Daily } \\
\text { Intake ( } \mu \mathrm{g} / \mathrm{kg} \\
\text { bw/day) }\end{array}$} & \multicolumn{4}{|c|}{ Mean Positive Samples } & \multicolumn{4}{|c|}{ Lower Bound Scenario } & \multicolumn{4}{|c|}{ Upper Bound Scenario } \\
\hline & & \multicolumn{2}{|c|}{$\begin{array}{c}\text { Mean PDI } \\
(\mu \mathrm{g} / \mathrm{kg} \text { bw/day }\end{array}$} & \multicolumn{2}{|c|}{$\%$ TDI } & \multicolumn{2}{|c|}{$\begin{array}{c}\text { Mean PDI } \\
(\mu \mathrm{g} / \mathrm{kg} \text { bw/day }\end{array}$} & \multicolumn{2}{|c|}{$\%$ TDI } & \multicolumn{2}{|c|}{$\begin{array}{c}\text { Mean PDI } \\
(\mu \mathrm{g} / \mathrm{kg} \text { bw/day }\end{array}$} & \multicolumn{2}{|c|}{$\%$ TDI } \\
\hline & & Males & Females & Males & Females & Males & Females & Males & Females & Males & Females & Males & Females \\
\hline DON & 1 & 0.25 & 0.30 & $25 \%$ & $30 \%$ & 0.052 & 0.063 & $5.2 \%$ & $6.3 \%$ & 0.055 & 0.067 & $5.5 \%$ & $6.7 \%$ \\
\hline $\begin{array}{l}\text { Total DON: } \\
\text { (DON+DOM- } \\
1)\end{array}$ & 1 & 0.76 & 0.92 & $76 \%$ & $92 \%$ & 0.322 & 0.393 & $32.2 \%$ & $39.3 \%$ & 0.329 & 0.402 & $32.9 \%$ & $40.2 \%$ \\
\hline ZEA & 0.25 & 1.23 & 1.50 & $492 \%$ & $600 \%$ & 0.49 & 0.6 & $196 \%$ & $240 \%$ & 0.53 & 0.64 & $212 \%$ & $256 \%$ \\
\hline $\begin{array}{c}\text { Total ZEA: } \\
\text { (ZEA, } \\
\text { ZEA-14 -Glc, } \\
\alpha \text { ZOL, } \\
\alpha \text { ZOL-14 } \\
\text {-Glc) }\end{array}$ & 0.25 & 10.87 & 13.27 & $4348 \%$ & $5308 \%$ & 3.49 & 4.25 & $1396 \%$ & $1700 \%$ & 3.66 & 4.46 & $1464 \%$ & $1784 \%$ \\
\hline OTA & 0.12 & 0.42 & 0.52 & $350 \%$ & $433 \%$ & 0.01 & 0.01 & $8.3 \%$ & $10.8 \%$ & 0.06 & 0.08 & $50 \%$ & $66.7 \%$ \\
\hline
\end{tabular}

Regarding OTA, only one sample was positive, but the PDI estimated was $0.42 \mu \mathrm{g} / \mathrm{kg}$ bw $/$ day for males and $0.52 \mu \mathrm{g} / \mathrm{kg}$ bw / day for females, exceeding the tolerable weekly intake (TWI) of $0.12 \mu \mathrm{g} / \mathrm{kg}$ bw/week; however, $8.3 \%$ and $10.8 \%$ of TDI was reached for males and females, respectively, when PDI was calculated under the LB scenario, and 50\% and 66.7\% in the UB (Table 2). Similar to these results, Solfrizzo et al. [19] observed that the TDI value calculated for OTA in urine exceeded the TWI fixed in $94 \%$ of volunteers. Contrary to these results, Heyndrickx et al. [6] observed that only $1 \%$ of Belgian volunteers' urine exceeded the TWI for OTA.

Finally, the PDI calculated for DON was a mean of $0.25 \mu \mathrm{g} / \mathrm{kg}$ bw $/$ day for males and $0.30 \mu \mathrm{g} / \mathrm{kg} \mathrm{bw} /$ day for females, reaching a percentage of up to $30 \%$ of the TDI fixed for DON. All DON metabolites were included in the assessment of the total DON amount (DON + DOM-1). Thus, PDI values increased to 0.76 and $0.92 \mu \mathrm{g} / \mathrm{kg}$ bw $/$ day for males and females, respectively, considering total DON, representing up to $92 \%$ of the TDI. These percentages of TDI decreased to up to $6.7 \%$ (DON) and $40.2 \%$ (total DON) when the PDI was calculated considering the LB and UB scenarios (Table 2).

A similar range was also observed by Warth et al. [24], who reported exposure percentages of TDI for total DON (free DON + DON-GlcAs) in the range of $38 \%$ to $220 \%$ in a study carried out in Austria. In a previous study, Rodríguez-Carrasco et al. [27] obtained similar results. These authors calculated the DON PDI as DON + DOM-1 levels and observed that these represented a range of between $6 \%$ and $107 \%$ of the established TDI. Furthermore, $8.1 \%$ of the total exposed subjects exceed the TDI limit. In Germany, Gerding et al. [28] observed that $12 \%$ of the urine samples exceeded the TDI value fixed for DON, considering DON-GlcA and DON biomarkers. Contrary to these results, Fan et al. [29] obtained a mean PDI value of $0.164 \mu \mathrm{g} / \mathrm{kg}$ bw / day for DON in a study performed in China, observing that only $0.4 \%$ of the population exceeded the TDI value.

Comparing these results with total diet studies, in Catalonia (a region of Spain), where mycotoxin dietary intake was assessed in order to characterize mycotoxin exposure under a deterministic methodology through the combination of data consumption with contamination levels, among all mycotoxins, OTA and DON constitute the most significant, reaching TDI percentages from 1 to $17 \%$ for OTA and up to $74 \%$ for DON [30]. These mycotoxins have also been reported in the present study as important biomarkers. However, ZEA estimated daily intakes (EDIs) reported by these authors were far below the TDI established. The approach proposed in the present study overcomes some disadvantages, such as the lack of information related to the individual exposure situation, toxicokinetics, and 
bioavailability. Moreover, mycotoxin distribution in food is not homogeneous and it is complicated to obtain accurate data on food consumption [31].

\section{Materials and Methods}

\subsection{Chemicals and Reagents}

Acetonitrile $(\mathrm{AcN})$ and methanol $(\mathrm{MeOH})$ were supplied by Merck (Darmstadt, Germany). Deionized water $(<18.2 \mathrm{M} \Omega \mathrm{cm}$ resistivity) was obtained in the laboratory using a Milli-QSP ${ }^{\circledR}$ Reagent Water System (Millipore, Beadford, MA, USA). Formic acid (reagent grade $\geq 95 \%$ ) was obtained from Sigma-Aldrich (St. Louis, MO, USA). Sodium chloride and ammonium acetate sorbent (analytical grade) were obtained from Merck. C18 was purchased from Phenomenex (Torrence, CA, USA). $\beta$-Glucuronidase Type H-1 from Helix pomatia (glucuronidase activity: $\geq 300,000$ units/g solid and sulfatase activity: $\geq 10,000$ units/g solid) was supplied by Sigma Aldrich. Syringe nylon filters (13 mm diameter $0.22 \mu \mathrm{m}$ pore size) were obtained from Analysis Vinicos S.L. (Tomelloso, Spain).

\subsection{Standards and Solutions}

The powder standards of ZEA, DON, DOM-1, and OTA were purchased from Sigma Aldrich and reconstituted in methanol at a concentration of $100 \mathrm{mg} / \mathrm{L}$. Then, individual stock of all analytes were prepared to obtain $20 \mathrm{mg} / \mathrm{L}$ in methanol and multianalyte working solutions of $2 \mathrm{mg} / \mathrm{L}$ were also used by diluting the individual stock solutions in methanol. The multianalyte working standard solution was used for standard calibration curves, matrix-matched calibration curves, and recovery assays. All standards were stored in darkness and kept at $-20^{\circ} \mathrm{C}$.

\subsection{Sampling}

Forty first-spot morning urine samples were collected during February and March 2019 from the Spanish population resident in Valencia region. Samples were acquired from a group of 20 males and 20 females within the age range of 18-65. All urine samples were collected into sterile plastic vessels. The samples were stored in a freezer $\left(-20^{\circ} \mathrm{C}\right)$ until analysis. The volunteers did not consume any special diet on the day prior to sample donation. All samples were anonymous, but participants indicated their age, weight, and gender, male (M) or female (F). A written and approved informed consent was obtained from the volunteers.

\subsection{Sample Preparation}

\subsubsection{Samples Enzymatic Hydrolysis}

All urine samples were centrifuged at $10,000 \mathrm{rpm}$ for $3 \mathrm{~min}$ at $4{ }^{\circ} \mathrm{C}$.

Samples were hydrolyzed according to a previous study [24]. For this, $1 \mathrm{~mL}$ of the previously centrifuged urine was collected in a $2 \mathrm{~mL}$ Eppendorf tube and $250 \mu \mathrm{L}$ of ammonium acetate buffer ( $1 \mathrm{M}, \mathrm{pH} 5)$ containing $20,000 \mathrm{U}$ of $\beta$-glucuronidase $/ \mathrm{mL}$ was added. The hydrolysis was performed with continuous stirring at $550 \mathrm{rpm}$ during $18 \mathrm{~h}$ at $37^{\circ} \mathrm{C}$.

\subsubsection{Salting-Out Assisted Liquid-Liquid Extraction (SALLE)}

After enzymatic hydrolysis, the sample was centrifugated and the upper layer was placed into a $15 \mathrm{~mL}$ conical bottom tube. Then, $1 \mathrm{~mL}$ of acetonitrile and a mixture of $0.3 \mathrm{~g}$ sodium chloride and $30 \mathrm{mg}$ of $\mathrm{C} 18$ sorbent were added. The mixture was vortexed for $30 \mathrm{~s}$ and centrifugated at $4000 \mathrm{rpm}$ for $3 \mathrm{~min}$ at $4{ }^{\circ} \mathrm{C}$. Finally, the upper layer was evaporated to near dryness under a nitrogen stream using a TurboVap LV Evaporator (Zimark, Hopkinton, MA, USA). The dry residue was reconstituted with $0.5 \mathrm{~mL}$ of $\mathrm{MeOH} / \mathrm{H} 2 \mathrm{O}(50 / 50 \mathrm{v} / v)$ and filtrated through a 13-mm/0.22- $\mu$ m nylon filter prior to LC-ESI-qTOF-MS analysis. 


\subsection{LC-ESI-qTOF-MS Analysis}

An Agilent 1200-LC system (Agilent Technologies, Palo Alto, CA, USA) equipped with a vacuum degasser, autosampler, and binary pump was used for the chromatographic determination. The column was Gemini ${ }^{\circledR}$ NX-C18 $(3 \mu \mathrm{M}, 150 \times 2 \mathrm{~mm}$ ID) and guard column C18 $(4 \times 2 \mathrm{~mm}$, ID; $3 \mu \mathrm{M})$ (Phenomenex). The mobile phases consisted of water (A) and acetonitrile (B), with $0.1 \%$ in formic acid for both. The gradient program was as follows: $0-6 \mathrm{~min}, 50 \% \mathrm{~B} ; 7-12 \mathrm{~min}, 100 \% \mathrm{~B} ; 13-20 \mathrm{~min}, 50 \% \mathrm{~B}$. The injection volume for standards and sample extracts was $5 \mu \mathrm{L}$ and the flow rate used was $0.2 \mathrm{~mL} / \mathrm{min}$. A mass spectrometry (MS) analysis was carried out using a 6540 Agilent Ultra-High-Definition Accurate-Mass q-TOF-MS coupled to the HPLC, equipped with an Agilent Dual Jet Stream electrospray ionization (Dual AJS ESI) interface in positive and negative ionization modes under the following conditions: drying gas flow (N2), $12.0 \mathrm{~L} \mathrm{~min}^{-1}$; nebulizer pressure, $50 \mathrm{psi}$; gas drying temperature, $370^{\circ} \mathrm{C}$; capillary voltage, $3500 \mathrm{~V}$; fragmentor voltage, $160 \mathrm{~V}$; and scan range $m / z, 50-1500$. Automatic MS/MS experiments were carried out using the following collision energy values: $m / z$ 100, $30 \mathrm{eV} ; m / z 500,35 \mathrm{eV} ; m / z$ 1000, $40 \mathrm{eV}$; and $m / z 1500,45 \mathrm{eV}$. Integration and data elaboration were performed using Mass Hunter Workstation software (Agilent Technologies). The analytical and spectrometric parameters are listed in Table 3.

Table 3. Retention times, molecular formula, measured neutral mass, observed mass in ionization mode, mass accuracy, and detection and quantification limits.

\begin{tabular}{|c|c|c|c|c|c|c|c|c|}
\hline Mycotoxin & $\begin{array}{l}\text { Retention } \\
\text { Time (min) }\end{array}$ & $\begin{array}{l}\text { Molecular } \\
\text { Formula }\end{array}$ & $\begin{array}{l}\text { Measured } \\
\text { Neutral } \\
\text { Mass }(m / z)\end{array}$ & \multicolumn{2}{|c|}{$\begin{array}{l}\text { Observed Mass in } \\
\text { Ionization Mode }\end{array}$} & $\begin{array}{l}\text { Accuracy } \\
(\Delta \text { ppm })\end{array}$ & $\begin{array}{l}\text { LOD } \\
\mathrm{ng} / \mathrm{mL}\end{array}$ & $\begin{array}{c}\mathrm{LOQ} \\
\mathrm{ng} / \mathrm{mL}\end{array}$ \\
\hline OTA & 7.3 & $\mathrm{C}_{20} \mathrm{H}_{18} \mathrm{ClNO}_{6}$ & 403.0839 & $(\mathrm{M}-\mathrm{H})^{-}$ & 402.0768 & 2.3 & 1.5 & 5 \\
\hline ZEA & 7.9 & $\mathrm{C}_{18} \mathrm{H}_{22} \mathrm{O}_{5}$ & 318.1467 & $(\mathrm{M}-\mathrm{H})^{-}$ & 317.1394 & 1.03 & 0.33 & 1 \\
\hline ZEA-14-Glc & 12.9 & $\mathrm{C}_{24} \mathrm{H}_{32} \mathrm{O}_{10}$ & 480.1941 & $(\mathrm{M}-\mathrm{H})^{-}$ & 479.1922 & 4.6 & - & - \\
\hline$\alpha \mathrm{ZOL}$ & 4.68 & $\mathrm{C}_{18} \mathrm{H}_{24} \mathrm{O}_{5}$ & 320.1623 & $(\mathrm{M}-\mathrm{H})^{-}$ & 319.1551 & -2.6 & 0.33 & 1 \\
\hline aZOL-14-Glc & 12.93 & $\mathrm{C}_{24} \mathrm{H}_{34} \mathrm{O}_{10}$ & 482.2151 & $(\mathrm{M}-\mathrm{H})^{-}$ & 481.2082 & 2.86 & - & - \\
\hline DON & 1.738 & $\mathrm{C}_{15} \mathrm{H}_{20} \mathrm{O}_{6}$ & 296.1277 & $(\mathrm{M}+\mathrm{HCOOH})^{-}$ & 341.1258 & -2.5 & 0.15 & 0.5 \\
\hline DOM-1 & 2.09 & $\mathrm{C}_{15} \mathrm{H}_{20} \mathrm{O}_{5}$ & 280.1303 & $(\mathrm{M}+\mathrm{H})^{+}$ & 281.1376 & 2.5 & 0.33 & 1 \\
\hline
\end{tabular}

MassHunter Qualitative Analysis program was employed to identify the mycotoxins and their metabolites in the urine samples, employing an accurate mycotoxin mass library, considering only the matching compounds identified with a minimum score of 80 . Then, matrix-matched calibration curves constructed at concentrations of the parent compound ranging from LOD to $1000 \mu \mathrm{g} / \mathrm{L}$ were used for effective quantification of samples.

\subsection{Risk Assessment Using Mycotoxins Biomarker Quantification}

The probable daily intakes (PDIs) of mycotoxins among the participants were obtained based on results of mycotoxin biomarkers in urine, employing the following equation according to Solfrizzo et al. [19]:

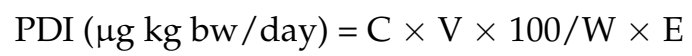

where $\mathrm{C}$ is the concentration of the mycotoxin biomarker in urine $(\mu \mathrm{g} / \mathrm{L}), \mathrm{V}$ is the mean volume of urine excreted in $24 \mathrm{~h}$, established in $1.5 \mathrm{~L}$ according to Rodríguez-Carrasco et al. [27]. $\mathrm{W}$ is the body weight $(\mathrm{kg})$, considering a mean of $67.2 \mathrm{~kg}$ for females and $82 \mathrm{~kg}$ for males based on the EFSA guidance [32]. E refers to the excretion rate (\%) of the corresponding mycotoxins, calculated as 10\% approximately for ZEA [14], around $72.3 \%$ for DON [16], and as $50 \%$ for OTA [18]. Variation in excretion rates, as well as urine flow rate excreted among individuals, have not been considered to calculate PDIs.

Two more scenarios were considered, lower bound scenario (LB) and upper bound scenario (UB) to process data below LOD according to EFSA recommendations [33]. In the 
LB scenario, zero was assigned when mycotoxins were not detected or were detected below the limit of quantification, while the limit of detection was assigned in the UB scenario.

Then, the calculated probable daily intakes (PDIs) were compared to the tolerable daily intakes fixed by the European Commission for the studied mycotoxins to assess the risk of exposure. A TDI of $0.25 \mu \mathrm{g} / \mathrm{kg}$ bw / day was established for ZEA [34] and of $1 \mu \mathrm{g} / \mathrm{kg}$ bw/day for DON [35], while a tolerable weekly intake (TWI) of $0.12 \mu \mathrm{g} / \mathrm{kg}$ bw/week has been fixed for OTA [36].

\section{Conclusions}

The analytical method based on salting-out liquid-liquid extraction and LC-ESI-qTOF allowed the detection of DON, ZEA, OTA, and their metabolites as DOM-1, ZEA-14-Glc, $\alpha Z O L$, and $\alpha$ ZOL-14-Glc in urine samples. The incidence of these biomarkers ranged from $3 \%$ for OTA to $53 \%$ for DOM-1, while the concentrations were comprised between $<$ LOQ and $49.45 \mathrm{ng} / \mathrm{m}$. The calculated PDI values for OTA and ZEA and their metabolites were, in some urine samples, greater than the established TDI values. These results confirm that these mycotoxins and their metabolites are still prevalent in urine and the development of biomarker approaches will greatly help in evaluating human exposure to mycotoxins, among other food contaminants.

Author Contributions: Formal analysis, investigation, writing-original draft preparation: D.C. and N.P. Conceptualization, supervision, writing—review and editing: H.B., E.F. and F.J.B. All authors have read and agreed to the published version of the manuscript.

Funding: This research was funded by the Spanish Ministry of Science and Innovation project (PID2020-115871RB-I00-ALI) and Carlos Antonio López-Paraguay fellowship and PhD program of University of Valencia "Atracció de Talent".

Institutional Review Board Statement: The study was conducted according to the guidelines of the Declaration of Helsinki. Participants provided their informed consent, and the processing of information was carried out according to the applicable data protection law.

Informed Consent Statement: Informed consent was obtained from all subjects involved in the study.

Conflicts of Interest: The authors declare no conflict of interest. The funders had no role in the design of the study; in the collection, analyses, or interpretation of data; in the writing of the manuscript, or in the decision to publish the results.

\section{References}

1. Da Rocha, M.E.B.; Freire, F.D.C.O.; Maia, F.E.F.; Guedes, M.I.F.; Rondina, D. Mycotoxins and their effects on human and animal health. Food Control 2014, 36, 159-165. [CrossRef]

2. Eskola, M.; Altieri, A.; Galobart, J. Overview of the activities of the European Food Safety Authority on mycotoxins in food and feed. World Mycotoxin J. 2018, 11, 277-289. [CrossRef]

3. Gavahian, M.; Pallares, N.; Al Khawli, F.; Ferrer, E.; Barba, F.J. Recent advances in the application of innovative food processing technologies for mycotoxins and pesticide reduction in foods. Trends Food Sci. Technol. 2020, 106, 209-218. [CrossRef]

4. Warth, B.; Sulyok, M.; Krska, R. LC-MS/MS-based multibiomarker approaches for the assessment of human exposure to mycotoxins. Anal. Bioanal. Chem. 2013, 405, 5687-5695. [CrossRef]

5. Turner, P.C.; Flannery, B.; Isitt, C.; Ali, M.; Pestka, J. The role of biomarkers in evaluating human health concerns from fungal contaminants in food. Nutr. Res. Rev. 2021, 25, 162-179. [CrossRef] [PubMed]

6. Heyndrickx, E.; Sioen, I.; Huybrechts, B.; Callebaut, A.; De Henauw, S.; De Saeger, S. Human biomonitoring of multiple mycotoxins in the Belgian population: Results of the BIOMYCO study. Environ. Int. 2015, 84, 82-89. [CrossRef] [PubMed]

7. Franco, L.T.; Petta, T.; Rottinghaus, G.E.; Bordin, K.; Gomes, G.A.; Alvito, P.; Assunção, R.; Oliveira, C.A.F. Assessment of mycotoxin exposure and risk characterization using occurrence data in foods and urinary biomarkers in Brazil. Food Chem. Toxicol. 2019, 128, 21-34. [CrossRef] [PubMed]

8. Njumbe Ediage, E.; Diana Di Mavungu, J.; Song, S.; Wu, A.; Van Peteghem, C.; De Saeger, S. A direct assessment of mycotoxin biomarkers in human urine samples by liquid chromatography tandem mass spectrometry. Anal. Chim. Acta 2012, 741, 58-69. [CrossRef] [PubMed]

9. Warth, B.; Sulyok, M.; Fruhmann, P.; Mikula, H.; Berthiller, F.; Schuhmacher, R.; Hametner, C.; Abia, W.A.; Adam, G.; Fröhlich, J.; et al. Development and validation of a rapid multi-biomarker liquid chromatography/tandem mass spectrometry method to assess human exposure to mycotoxins. Rapid Commun. Mass Spectrom. 2012, 26, 1533-1540. [CrossRef] 
10. Vidal, A.; Cano-Sancho, G.; Marín, S.; Ramos, A.J.; Sanchis, V. Multidetection of urinary ochratoxin A, deoxynivalenol and its metabolites: Pilot time-course study and risk assessment in Catalonia, Spain. World Mycotoxin J. 2016, 9, 597-612. [CrossRef]

11. Vidal, A.; Mengelers, M.; Yang, S.; De Saeger, S.; De Boevre, M. Mycotoxin Biomarkers of Exposure: A Comprehensive Review. Compr. Rev. Food Sci. Food Saf. 2018, 17, 1127-1155. [CrossRef]

12. Li, C.; Deng, C.; Zhou, S.; Zhao, Y.; Wang, D.; Wang, X.; Gong, Y.Y.; Wu, Y. High-throughput and sensitive determination of urinary zearalenone and metabolites by UPLC-MS/MS and its application to a human exposure study. Anal. Bioanal. Chem. 2018, 410, 5301-5312. [CrossRef] [PubMed]

13. Franco, L.T.; Khaneghah, A.M.; Hwa, S.; Lee, I.; Augusto, C.; Oliveira, F. Toxin Reviews Biomonitoring of mycotoxin exposure using urinary biomarker approaches: A review Biomonitoring of mycotoxin exposure using urinary biomarker approaches: A review. Toxin Rev. 2019, 1-21. [CrossRef]

14. Fleck, S.C.; Churchwell, M.I.; Doerge, D.R.; Teeguarden, J.G. Urine and serum biomonitoring of exposure to environmental estrogens II: Soy isoflavones and zearalenone in pregnant women. Food Chem. Toxicol. 2016, 95, 19-27. [CrossRef]

15. Papageorgiou, M.; Wells, L.; Williams, C.; White, K.; De Santis, B.; Liu, Y.; Debegnach, F.; Miano, B.; Moretti, G.; Greetham, S.; et al. Assessment of Urinary Deoxynivalenol Biomarkers in UK Children and Adolescents. Toxins 2018, 10, 50. [CrossRef]

16. Turner, P.C.; White, K.L.M.; Burley, V.J.; Hopton, R.P.; Rajendram, A.; Fisher, J.; Cade, J.E.; Wild, C.P. A comparison of deoxynivalenol intake and urinary deoxynivalenol in UK adults. Biomarkers 2010, 15, 553-562. [CrossRef] [PubMed]

17. Ali, N.; Muñoz, K.; Degen, G.H. Ochratoxin A and its metabolites in urines of German adults-An assessment of variables in biomarker analysis. Toxicol. Lett. 2017, 275, 19-26. [CrossRef] [PubMed]

18. Schlatter, C.H.; Studer-Rohr, J.; Rasonyi, T.H. Carcinogenicity and kinetic aspects of ochratoxin A. Food Addit. Contam. 1996, 13, 43-44. [PubMed]

19. Solfrizzo, M.; Gambacorta, L.; Visconti, A. Assessment of Multi-Mycotoxin Exposure in Southern Italy by Urinary Multi-Biomarker Determination. Toxins 2014, 6, 523-538. [CrossRef] [PubMed]

20. Šarkanj, B.; Ezekiel, C.N.; Turner, P.C.; Abia, W.A.; Rychlik, M.; Krska, R.; Sulyok, M.; Warth, B. Ultra-sensitive, stable isotope assisted quantification of multiple urinary mycotoxin exposure biomarkers. Anal. Chim. Acta 2018, 1019, 84-92. [CrossRef]

21. Turner, P.C.; Hopton, R.P.; Lecluse, Y.; White, K.L.M.; Fisher, J.; Lebailly, P. Determinants of urinary deoxynivalenol and de-epoxy deoxynivalenol in male farmers from normandy, France. J. Agric. Food Chem. 2010, 58, 5206-5212. [CrossRef]

22. Turner, P.C.; Hopton, R.P.; White, K.L.M.; Fisher, J.; Cade, J.E.; Wild, C.P. Assessment of deoxynivalenol metabolite profiles in UK adults. Food Chem. Toxicol. 2011, 49, 132-135. [CrossRef]

23. Cunha, S.C.; Fernandes, J.O. Development and validation of a gas chromatography-mass spectrometry method for determination of deoxynivalenol and its metabolites in human urine. Food Chem. Toxicol. 2012, 50, 1019-1026. [CrossRef]

24. Rodríguez-Carrasco, Y.; Moltó, J.C.; Mañes, J.; Berrada, H. Development of microextraction techniques in combination with GC-MS/MS for the determination of mycotoxins and metabolites in human urine. J. Sep. Sci. 2017, 40, 1572-1582. [CrossRef]

25. Warth, B.; Sulyok, M.; Fruhmann, P.; Berthiller, F.; Schuhmacher, R.; Hametner, C.; Adam, G.; Fröhlich, J.; Krska, R. Assessment of human deoxynivalenol exposure using an LC-MS/MS based biomarker method. Toxicol. Lett. 2012, 211, 85-90. [CrossRef] [PubMed]

26. Niknejad, F.; Escrivá, L.; Adel Rad, K.B.; Khoshnia, M.; Barba, F.J.; Berrada, H. Biomonitoring of Multiple Mycotoxins in Urine by GC-MS/MS: A pilot study on patients with esophageal cancer in Golestan province, Northeastern Iran. Toxins 2021, 13, 243. [CrossRef] [PubMed]

27. Rodríguez-Carrasco, Y.; Moltó, J.C.; Mañes, J.; Berrada, H. Exposure assessment approach through mycotoxin/creatinine ratio evaluation in urine by GC-MS/MS. Food Chem. Toxicol. 2014, 72, 69-75. [CrossRef]

28. Gerding, J.; Cramer, B.; Humpf, H.-U. Determination of mycotoxin exposure in Germany using an LC-MS/MS multibiomarker approach. Mol. Nutr. Food Res. 2014, 58, 2358-2368. [CrossRef]

29. Fan, K.; Xu, J.; Jiang, K.; Liu, X.; Meng, J.; Di Mavungu, J.D.; Guo, W.; Zhang, Z.; Jing, J.; Li, H.; et al. Determination of multiple mycotoxins in paired plasma and urine samples to assess human exposure in Nanjing, China. Environ. Pollut. 2019, 248, 865-873. [CrossRef] [PubMed]

30. Ramos, A.J.; Cano-Sancho, G.; Sanchis, V.; Marin, S. Evaluación de la exposición humana a Microtoxinas: Estudio global en la población de Cataluña (España). Revista Bio Ciencias 2012, 2, 45-57.

31. Arce-López, B.; Lizarraga, E.; Vettorazzi, A.; González-Peñas, E. Human biomonitoring of mycotoxins in blood, plasma and serum in recent years: A review. Toxins 2020, 12, 147. [CrossRef] [PubMed]

32. Committee, E.S. Guidance on selected default values to be used by the EFSA Scientific Committee, Scientific Panels and Units in the absence of actual measured data. EFSA J. 2012, 10, 32.

33. European Food Safety Authority (EFSA). Management of left-censored data in dietary exposure assessment of chemical substances. EFSA J. 2010, 8, 1557.

34. EFSA CONTAM Panel (EFSA Panel on Contaminants in the Food Chain) Scientific Opinion on the risks for human and animal health related to the presence of modified forms of certain mycotoxins in food and feed. EFSA J. 2014, 12, 107. 
35. European Commission Scientific Committee on Food Opinion of the Scientific Committee on Food on Fusarium toxins. Part 6: Group Evaluation of T-2 Toxin, HT-2 Toxin, Nivalenol and Deoxynivalenol (Adopted by the SCF on 26 February 2002); European Commission: Brussels, Belgium, 2002.

36. EFSA CONTAM Panel (EFSA Panel on Contaminants in the Food Chain) Opinion of the Scientific Panel on contaminants in the food chain [CONTAM] related to ochratoxin A in food. EFSA J. 2006, 4, 365. [CrossRef] 